\title{
Cartas de mujeres en documentos americanos coloniales*
}

\author{
Mariano Franco Figueroa** \\ Universidad de Cádiz, España
}

\begin{abstract}
Resumen
Nos basamos en el estudio lingüístico de siete cartas seleccionadas del Archivo General de Indias. El interés reside en la firma de sus redactores, en este caso mujeres, que responden a sus parientes en torno a los traslados al Nuevo Mundo. El análisis de los fenómenos lingüísticos, grafemáticos, fonéticos, gramaticales y léxicos, muestra variantes de registros menos formales y en muchos casos adscritas a situaciones de menor cultura de sus amanuenses, aparte de las posibles connotaciones de estilo que la condición femenina explique. La tipología textual obedece a la estructura intimista de estas misivas entre familiares, pero trasluce expresiones y usos contrastivos desde una perspectiva sociolingüística, con preferencias en los recursos idiomáticos de las mujeres inmersas en emigración colonial americana.
\end{abstract}

Palabras clave: español de América, historia de la lengua, variedad de registros.

* Del proyecto FFI2008-02718/FILO, MICINN.

** Para correspondencia, dirigirse a: Mariano Franco Figueroa (mariano.franco@uca.es), Departamento de Filología, Facultad de Filosofía y Letras, Universidad de Cádiz, Avda. Gómez Ulla, 1, 11003 Cádiz, España. 


\title{
WOMEN'S LETTERS IN AMERICAN COLONIAL DOCUMENTS
}

\begin{abstract}
We base this paper on the linguistic study of seven letters selected from the Archivo General de Indias. Their interest resides in the signature of their writers, in this case women, who answer their relatives about their move to the New World. The analysis of the linguistic, graphemic, phonetic, grammatical and lexical phenomena, shows variants of less formal records and in many cases attributable to the poor cultural level of their scribes, as well as to the possible connotations of style that the feminine condition explains. The textual typology follows the intimist structure of these missives between relatives, but it reveals contrastive expressions and uses from a sociolinguistic perspective, with preferences in the idiomatic resources of the women immersed in American colonial emigration.
\end{abstract}

Key words: American Spanish, history of the language, variety of records.

Recibido: 25/08/11. Aceptado: 12/10/11.

\section{INTRODUCCIÓN}

La correspondencia particular entre individuos emigrados a América apenas tiene cabida en la inmensa documentación del Archivo General de Indias, a no ser que se encuentre como testimonios y referencias en los procesos de la Administración, como peticiones de mercedes, licencias, pleitos o causas judiciales ${ }^{1}$. Poco interés oficial, salvo su valor probatorio legal, representan estas cartas que ponen en contacto a amigos y familiares más cercanos, pero alejados del Nuevo Mundo. Sin embargo, desde la perspectiva filológica, ofrecen la posibilidad de acercarse con mayor certeza a los registros menos formales y, por tanto, a su norma de habla y permiten rastrear los fenómenos

Esta es la razón por la que la mayoría de las cartas particulares se recogen en legajos que pertenecen a la sección de Contratación y a la de Indiferente General, como confirma la selección de misivas coloniales que realizan tanto Enrique Otte (1996) como Isabelo Macías y Francisco Morales Padrón (1991). 
lingüísticos ajenos a los modelos tipificados en los escritos administrativos $\mathrm{y}$ en los textos particulares que respondían a requerimientos oficiales entre partes. Se trata de una comunicación privada, entre personas que mantienen estrechas relaciones de confianza y de familiaridad, por amistad o parentesco, en la que por las estrategias del discurso propio se recurre a expresiones más populares y a un tono conversacional que acoge sin ambages sentimientos de afecto y de contrariedades emocionales.

La importancia de este género epistolar en la documentación del archivo hispalense americanista no ha pasado inadvertida ni para historiadores ni para filólogos. El acercamiento lingüístico del profesor Peter Boyd-Bowman (1975), que transcribe tres cartas privadas de emigrantes a Indias, incide en la caracterización fonética de una zona americana, la caribeña, y en su peculiar impronta dialectal de tendencia meridional peninsular. Desde la perspectiva histórica, son conocidos los estudios de Otte (1996), sobre 650 documentos epistolares particulares, acotados entre los años 1540 y 1616, y de Macías y Morales Padrón (1991), con la edición de cartas escritas desde América, fechadas entre 1700 y 1800, que muestran apreciaciones sobre la tipología de los textos y observaciones que incluyen aspectos culturales y sociológicos imprescindibles para la comprensión de la sociedad colonial y sus formas y costumbres culturales, entre las que se encuentra, claro está, la de su lengua ${ }^{2}$. En este sentido, sin menoscabo del valor documental antes comentado, nos acercamos a este fondo epistolar con un interés filológico que exige la visualización concreta de los signos escritos en sus folios originales, como premisa de todo análisis lingüístico histórico de manera que sustente con fiabilidad los datos ante la decidida modernización de los textos transcritos por estos autores.

Escogemos para nuestro propósito cartas de mujeres, con la convicción de que la información que nos proporcionan nos confirme el proceso que liga las identidades lingüísticas peninsulares, especialmente meridionales, y la americana en su desarrollo histórico, y permita colegir modelos de discurso contrastivo por razones diastráticas. Estos textos manuscritos representan el lenguaje espontáneo y menos planificado, caracterizado por

2 En el aprovechamiento filológico de estos corpus había insistido Frago Gracia (1987), que dirige la tesis doctoral de Ruiz Fernández (2002), centrada en los aspectos fonéticos de las cartas, y que él mismo comenta en algunos de sus trabajos filológicos (1999). También García Moutón (1999a), Bentivoglio (2002), o Cano Aguilar (2000) utilizan esta recopilación epistolar para indagar sobre cuestiones de tratamientos, en los dos primeros casos, y como pretexto para un análisis filológico, en el último. Igualmente, hemos utilizado algunas cartas seleccionadas por estos historiadores para corroborar los meridionalismos fonéticos más extendidos por América, especialmente el del seseo (2010). 
sus manifestaciones orales que escapan de la codificación de lo escrito y por sus registros de habla que evidencian, por el tema, la intencionalidad y el tono informal, una tipología coloquial. A estas diferencias de habla se suman las que conlleva el nivel sociológico de sus autoras, mujeres que, en este contexto histórico, pertenecen a un grupo social con una determinada educación funcional y con unas escasas perspectivas de formación intelectual $^{3}$. La asignación del papel de acompañante matrimonial ${ }^{4} \mathrm{y}$ de salvaguarda de la entidad familiar explica la mayor participación emocional en los contenidos informativos de las misivas y la expresividad manifiesta de las formas lingüísticas elegidas.

\section{REFERENCIA DOCUMENTAL}

Las cartas seleccionadas se encuentran digitalizadas y sus imágenes permiten una lectura fácil ${ }^{5}$. Su extensión, por el tipo de discurso y objetivo descritos,

3 A este papel social de la mujer y a la limitación histórica de su derecho a optar a una educación funcional y a una formación intelectual igualitarias achaca García Moutón (1999) las diferencias lingüísticas por razón de sexo. No cabe duda, entonces, de que la evolución cultural aminora la distancia que separa a hombres y mujeres y que la incorporación laboral y pública del sector femenino a la sociedad moderna difumina los pretendidos contrastes lingüísticos, pero aún persisten los recursos preferentes que distinguen el habla de ambos sexos.

4 Paradójicamente, el necesario asentamiento familiar en América coloca a la mujer en el papel de sujeto imprescindible para el sostén económico y político de la vida colonial, cuestión que le permite gestionar su opción de reunirse o no con su esposo, al que la Administración castigaría severamente, a penas de galera incluso, si marchaba a Indias como soltero. Las peticiones del esposo para una pronta reunión en América marcará el centro informativo de la mayor parte de las cartas privadas, con súplicas y con los consejos propios para la realización del viaje. Ejemplo de esta preocupación es la carta que, desde Veracruz, envía Juan de Aguilar a su mujer, Juana Delgada, residente en Sevilla (Indiferente General del Archivo General de Indias, 2052, N. 39, de 16 de enero de 1569, según Otte, número 195): “yo quedo qual Dios me remedie, pues quedo preso y con vnos grillos por casado y esto, señora, bien se pudiera aver remediado con buestra venida" (f. 15), "mi alma, por vida buestra y mía que agáys lo que os enbiado a rogar en mis cart[as], en que vengáys acá por qualquier manera que pudierdes, porque, mira, mi alma, no penséis que venir acá ques aora muncho, no es nada porque en la era de aora vienen munchas señoras con quien podéys venir" (f. 16).

5 Si bien los textos pueden identificarse por foliación, recto y verso, hemos adoptado para las cartas la referencia de las imágenes porque permite una más rápida localización en la totalidad del documento en el que se hallan inmersas. No obstante, en las citas de ejemplos usamos la abreviatura f. Mantenemos las grafías originales, con normalización de las mayúsculas y con las abreviaturas en cursiva. 
no sobrepasa las cuatro páginas, con datos fiables acerca de la identificación de su autoría y persona receptora, y sobre su procedencia local y destino. Sin obviar los problemas que conlleva la identificación del amanuense, en muchos casos mero agente al dictado de otra persona, con el redactor del escrito, la caligrafía del cuerpo y la de la rúbrica confirman la coincidencia del individuo. Las localidades de origen y recepción de las cartas permiten colegir asimismo la ascendencia y vecindad de estos emigrantes y de sus parientes, con la consiguiente certeza de sus adscripciones regionales y sus inevitables variantes lingüísticas. Todas las piezas epistolares están fechadas en torno a la mitad del siglo XVIII, cuando la variedad lingüística americana se halla consolidada y sus rasgos dialectales conforman habitualmente la norma de sus hablantes.

Las dos primeras misivas tienen como remitentes a Luisa Yáñez y su esposo, Pedro de Vilalongue, residentes en La Habana, y se dirigen a su hermana Antonia Yáñez. Ambas hermanas son extremeñas, de Mérida. Las cartas aparecen rubricadas por Luisa de Yáñez ${ }^{6}$, una fechada el dos de septiembre de 1742, y otra del ocho de octubre de 1742, que incluye en la firma el nombre del esposo, escritas desde su lugar de residencia caribeño $\mathrm{y}$, por su contenido, se deduce que fue redactada por ambos esposos: "su ermano y ermana que de corasón la estiman" (f. 9), "sus más afectos ermano y ermana" (f. 13).

La segunda pieza epistolar pertenece a Bernarda Enríquez ${ }^{7}$, residente en Buenos Aires, que se dirige a su hija Antonia Josefa Domínguez. En el documento se reconoce que Antonia Domínguez es natural de la ciudad de la Santísima Trinidad, puerto de Santa María de Buenos Aires, y que se encuentra en Cádiz, por lo que pide licencia para ir a Buenos Aires, desde donde la solicita su madre. La carta, fechada en Buenos Aires, a ocho de noviembre de 1744, lleva la rúbrica de su autora y presenta un cambio de letra en los últimos renglones del folio 7, concretamente en los relativos a la despedida, "y seso no de rogar a Dios...", caligrafía que coincide con la de la firma y con la identificación final del destinatario, "Mi hija D. ${ }^{a}$ Antonia Josepha Domingues".

El tercer escrito de correspondencia lleva la firma de Rosalía de Gasca ${ }^{8}$, natural de Antequera, en el valle de Oaxaca (México), y casada con Rafael de Godoy, ambos vecinos de esta ciudad. Esta criolla dirige la misiva a su

6 Contratación, 5487, N. 3, R. 11, fs. 7-9 y 11-13 (Macías y Morales Padrón, números 186 y 187$)$.

7 Contratación, 5488, N. 3, R. 20, fs. 5 y 7 (Macías y Morales Padrón, n. ${ }^{0} 139$ ).

8 Contratación, 5488, N. 3, R. 13, fs. 13-15 (Macías y Morales Padrón, n. ${ }^{\circ} 88$ ). 
marido, residente ahora en el pueblo sevillano de Utrera, de donde era natural, por asuntos de herencias familiares. Está fechada el veintitrés de marzo de 1745, con su rúbrica, posiblemente desde su ciudad mexicana.

Las siguientes cartas, en orden cronológico, tienen como titular a Isabel Martínez Romero y Palenque ${ }^{9}$, andaluza de Tarifa, ahora residente en México, casada con el comerciante José David. Se trata de dos misivas que envía a su madre, una con fecha de veintidós de mayo de 1750 y otra sin datación, aunque ambas debieron salir del lugar de residencia. Las cartas se encuentran en el expediente de licencia, fechado en 1752, para que pase a México una hermana suya, Blasinda Romero y Palenque, como comenta el documento de licencia, con la confirmación típica de su descripción física:

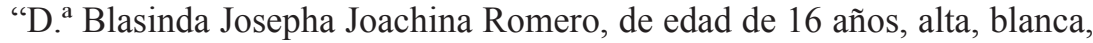
delgada, cariaguileña, ojos pardos" (f. 47).

El último texto epistolar objeto de nuestro estudio se debe a Antonia María Manrique $^{10}$, residente en Guatemala, que escribe la carta a su hijo Francisco Palomo, criollo natural de la ciudad de Guatemala y que actualmente, por razones de estudios, se encuentra en Granada, en colegio del Sacromonte. La fecha es de uno de mayo de 1775, desde Guatemala, y viene rubricada por su autora.

\section{EL DISCURSO FEMENINO}

No cabe duda de que los estudios lingüísticos han tenido, por lo general, como representantes básicos a sujetos masculinos y de que las diferencias en el habla femenina se perciben en muchos casos como desvíos en sus registros. Si embargo, aparte de la reivindicación histórica y social de la mujer, que ha aumentado los tratados al respecto, el interés por conocer los rasgos que la diferencian en la lengua tiene una tradición dialectológica $\mathrm{y}$, últimamente, a estas referencias dialectales se les añaden criterios metodológicos complementarios con perspectivas sociolingüísticas ${ }^{11}$.

9 Contratación, 5494, N. 1, R. 26, fs. 3-8, 7-10 y 47 (Macías y Morales Padrón, n. o 30 y 31 ).

10 Contratación, 5520, N. 1, R. 31, fs. 1-4 (Macías y Morales Padrón 104).

11 Remitiéndonos a unos ejemplos, podemos recordar que la elaboración de atlas lingüísticos se apoyaba también en informantes femeninos, más tradicionales y conservadores de la cultura popular. Además, en la dialectología hispana, hay bibliografía científica sobre el habla de las mujeres, tanto en estudios concretos, como los de Gregorio Salvador o Manuel 
Al valor puramente etnológico de estas cartas, con datos relativos al papel de la mujer en la colonia y de las costumbres sociales del momento histórico, se suman las constantes propias de este discurso textual, en el que predominan los rasgos caracterizadores de la comunicación más particular: el parentesco entre los interlocutores, el saber compartido de su contexto cultural y social y la relación de igualdad o de desigualdad en la que se hallan, con la consiguiente revelación de actitudes emocionales y de finalidades concretas por cada parte. Desde el punto de vista lingüístico, se trata de un discurso que, por su tema e intencionalidad, recurre a las estrategias de la oralidad $^{12}$.

La tipología estructural de las cartas familiares muestra unos moldes básicos, raramente modificados. Abre con la cruz del encabezamiento, a la que sigue la fórmula estereotipada del tratamiento del destinatario. El cuerpo de la información revela el contexto privado y familiar en el que se desarrollan las relaciones personales y el objetivo último de la misiva, la preparación del viaje que culmine con el reencuentro de cónyuges y de parientes. El texto termina con la despedida, la referencia local y la fecha de su realización. El colofón de la misiva reitera la persona a la que va dirigida y finaliza con la rúbrica de su autor. A veces, en los márgenes se recogen addendas y notas aclaratorias o simplemente una continuación del escrito, obligada por la falta de espacio en el folio y la necesidad de escatimar el papel empleado, como sucede en las cartas de Isabel Martínez, de Rosalía de la Gasca y de Antonia María Manrique. Este mismo carácter formulario difumina las posibles diferencias en el lenguaje que emplean hombres y mujeres, y el ejemplario queda limitado, como se sabe, a cuestiones de preferencias lingüísticas en situaciones concretas. En el caso que nos ocupa, las informaciones que se manifiestan en las cartas de estas mujeres nos acercan a cuestiones sociológicas y culturales propias de la relación entre familiares y concretamente entre los miembros del matrimonio, lo que no

\footnotetext{
Alvar, referidos a poblaciones granadinas, José Antonio Samper o Manuel Almeida, sobre ciudades canarias, como en los atlas lingüísticos y etnográficos de Andalucía, Canarias, Castilla-La Mancha, etc. (García Moutón 1999: 33-49).

12 Martín Zorraquino (1993) señalaba la incidencia de factores procedentes del ámbito de la psicolingüística, estrechamente relacionados con los de tipo social, en el habla de las mujeres. Así, estas circunstancias explican la competencia comunicativa y las técnicas expresivas de las que hacen uso y justifican su acercamiento al ámbito de la oralidad como consecuencia de la carencia de una instrucción cultural básica (1999). Oesterreicher (2004: 747) recuerda los mecanismos que caracterizan la competencia escrita de impronta oral de algunos textos que manifiestan la deficiente formación cultural de quien escribe. Se trata de rasgos que determinan la inmediatez comunicativa y que pertenecen a la lengua hablada en general y a registros diafásicos, diastráticos o dialectales como variantes ajenas a las normas escriturarias.
} 
impide que se constaten datos externos como el del temor a las desgracias en la travesía motivado bien por la incertidumbre del viaje por mar, bien por la situación de guerras europeas, como aparece en la carta de Luisa Yáñez, "no tuviese el trabaxo de pasar la mar" (f. 9), "de no auerse determinado vuestra merced a venir por acá a sido por los motivos de las guerras" (f. 8 ), aunque siempre con recomendaciones de aliento, como hace Antonia María Manrique a su hijo, "dicen que en la venida no hay riesgo como en la ida" (f. 3).

Las expresiones afectivas que pueden caracterizar a este tipo de escrito, en general, coinciden con las que emplean igualmente los redactores masculinos. En cualquiera de las cartas de estos emigrados se atestiguan los encabezamientos y despedidas avalados por la tradición epistolar familiar. Así se dirige Antonio de Espinosa y Arguello ${ }^{13}$ a Jacinta García Tineo, natural de Cádiz, en 1752, con los apelativos compadre, comadre, de mayor uso andaluz, como confirmaba ya el primer diccionario académico, y americano, especialmente entre las clases populares: "Mi mui amada comadre y señora" (f. 1), "Su más afecto compadre y señor" (f. 3). Quizás las razones sociales que afectan al mayor protagonismo, que no importancia, del hombre en las relaciones matrimoniales justifiquen que Juan Barbero ${ }^{14}$, emigrante jiennense, antiguo soldado y ahora pulpero en La Habana, junto al vocativo afectivo y de cortesía interesada, "Esposa y querida mía" (f. 1r.), manifieste reproches que condicionan la expresividad sentimental, con duras referencias al talante de su mujer, Francisca de Cáceres, "te ha dado el diablo ese natural que con naide te sabes sobrellevar bien" (f. 6 r.), porque "más estimas el resevir dinero que no cartas" (f. 1r.), y con un exabrupto claramente revelador de la dureza en su recriminación: "besando manos que merecían ser cortadas" (f. 5 v.).

El primer escrito de la extremeña Luisa Yáñez a su hermana recoge el deseo de tenerla con ella y con su esposo en América y su disponibilidad para organizar y hacer frente a los gastos del pasaje: "y así, tocante de su pasage, si no hallara alguna conveniensia de alguna familia y quisieres determinarse en venir, siempre quedo obligado a corresponder a su pasage" (f. 8). En la segunda misiva, ambos autores justifican la falta de comunicación con la hermana por las continuas pérdidas de los envíos, "conque es desgrasia nuestra de que las cartas se pierden de parte y otra" (f. 12), e insisten en su

3 Contratación, 5494, N. 1, R. 24, licencia de embarque para Buenos Aires.

14 Contratación, 5491, N. 3, R. 3, fs. 1-7 (recto y vuelto), desde La Habana, tres cartas, una sin fecha aunque presumiblemente anterior y cercana a otras del mismo indiano, de 1745 y 1749. 
propósito de traerla en su compañía: "tocante a su venida por acá, puede estar asegurada que estamos siempre en el mismo dictamen y que nunca faltaremos a lo propuesto" (f. 12).

Nuestra redactora, Luisa Yáñez, se refiere en su primera carta a su hermana como "Ermana y querida mía", "Ermana mía" (f. 7); con una mayor expresividad en el tratamiento más íntimo de la segunda, "Ermana de mi corasón" (f. 11). La despedida revela idéntico ánimo afectivo y cariñoso, "Besa la mano de vuestra merced su ermano y ermana, que de corasón la estima y verla desean quanto antes", "A mi querida hermana Antonia Yáñez" (f. 9), aunque en la segunda carta le dispense un trato más formal con el cultismo afecto: "Besa la mano de vuestra merced sus más afectos ermano y ermana" (f. 13). En el cuerpo de las dos misivas, el registro más conversacional viene avalado por el empleo de giros coloquiales y fraseología popular, como la locución hiperbólica hasta la muerte ("siempre quedamos con las mismas yntensiones asta la muerte" f. 8), o las expresiones de contenido religioso: "a Dios grasias", "mientras Dios nos diere vida" (f. 7). En lo que toca a la forma del tratamiento, esta responde al esquema respetuoso de vuestra merced, junto con los posesivos asociados su, suya, y la referencia al clítico le: "Ermana mía, resevimos las de vuestra merced", "la de mi esposa, su hermana" (f. 7), "tocante de su pasage" (f. 8), "Receví su fauoresida", "quexarse que no le han escrito" (f. 11), "con bastante ansias le estamos esperando" (f. 12), este caso con el leísmo personal tan característico de las tierras extremeñas. La forma verbal empleada es la propia del uso deferente: "las quales selebramos mucho por saber que gose de salud" (f. 7), "quisiere determinarse en venir" (f. 8). Cuando se refiere a una persona ajena a la familia, a la que se le debe respeto y sumisión por su autoridad, se emplea el término amo, "nuestro amo Julián, el contramaestre de Tallapiedra" (f. 9).

La relación maternal queda reflejada en las cartas de Bernarda Enrique a su hija, de Isabel Martínez a su madre, y de Antonia María Manrique a su hijo. En la primera, el tratamiento de entrada contiene la intensificación sentimental que la coordinación del participio conlleva: "Yja i querida de mi corasón" (f. 5), y los apelativos, algunos con genitivos atributivos, que aparecen denotan esa misma emotividad: "ija de mi alma" (f. 5), "yja mía" (f. 7). El discurso más expresivo y conversacional se observa en las intensificaciones afectivas, "mil deseos de berte", "mil memorias" (f. 5), y en la intimidad de las referencias religiosas: "le tengo prometido a la birgen de Lugán de irle a serbirla con bos propia", "le estoi sirbiendo a la birgen del rosario" (f. 5), etc. Aunque en la despedida se manifiesta cierta formalidad, "Buestra madre que más te estimará verter que qescriuirte" (f. 7), en la designación del destinatario reitera la familiaridad, "Mi hija doña Antonia 
Josepha Domingues" (f. 7). El esquema de confianza, con el empleo de marcas de segunda persona, es el único que se usa para el trato con su hija: "y te allen con la salu que io para mi deseo", "y la de tu ermano", "resebí la tuia", "lo que nos quisieres mandar", "los trabajos que me representas" (f. 5), etc. Cercana al discurso coloquial resulta la reiteración del cuantificador indefinido en el contexto "yja mía, todas tus tías y primas y sobrinas, todas se te encomiendan de corasón" (f. 7).

Isabel Martínez se dirige a su madre con las expresiones "Madre de mi corazón" (f. 3), "Madre y querida de mi corazón" (f. 7), y se despide con el respeto acostumbrado, tanto en el primero de los escritos, "Hija de vuestra merced, que le estima y ber desea" (f. 6, al margen), como en el segundo, "hija de su vuestra merced que su mano besa" (f. 10). La relación filial manifiesta su confianza en los vocativos que repite, madre (fs. 3 y 4 ), madresita (fs. 7 y 8). A la coloquialidad de la intensificación exagerada de los sentimientos, "Dios guarde vuestra merced mil años" (f. 6), se suma un discurso popular, plagado de frases repetidas, "que abía ydo para buscar un pedaso de pan" (f. 3), "que acá no se alla el dinero en la calle" (fs. 3 y 4), algunas de frecuencia contrastada en el habla femenina como "aunque yo no tubiera qué poneme" (f. 9), y con apreciaciones subjetivas más cercanas a lo conversacional, a una interacción virtual entre interlocutores, "porque, aunque, es una rediculés, quien le da esos si pudiera le diera muncho más" (fs. 4 y 5), "ya beo que no puede ser si no es por contingencia de que a su padre le dé la gana de mandarlo cuando sea grande" (f. 5), "porque como ya sé lo que son hijos" (f. 6), "pero no se puede todo lo que se quiere", "parese que vuestra merced no conose la hija que tiene", "aunque me esté mal e desilo aora" (f. 9), etc. También en este caso, se confirman contextos que denotan la sumisión social de la mujer: "no digo yo que no lo trajesen, pero ante o traiéndolo, en casados una mujer no es dueño de nada" (f. 4), "yo, con la cicutancia de que tengo el aparo de mi esposo y esas pobre no tienen otro que es el de Dios" (f. 5), "mira que anque yo soy su hermana soi casada y asín que a de estar en el etendré, que si biene biene a estar sugeta a mí" (f. 6), este último con la apertura del imperativo sensorial tan abundante en los registros conversacionales. De nuevo se repiten los rasgos propios del uso cortés antes mencionado, ahora con la presencia la forma actual usted: "le mando vuestra merced 100 pesos y un cajonsito de abanico", "la recomendación que ute me ase dél", "su sobrino de vuestra merced" (f. 3), "por saber que vuestra merced gosa de perfecta salud" (f. 7), etc.

Antonia María Manrique muestra un tratamiento maternal estereotipado, con menos intensidad emotiva en el encabezamiento, "Querido hijo Francisco Josef" (f. 1), y que luego cambia en la despedida, más cercana y sentimental: "Tu amante y triste madre que berte desea" (f. 4, al margen). La afectividad 
se repite en el vocativo y en el diminutivo cariñoso, "y adiós, hijo mío", "Recibe memorias de mamaíta, tus hermanos y hermanas" (f. 4), y el ámbito sentimental se confirma con las adjetivaciones intensivas, "corazón tan acongojado e inquieto" (f. 2). La relación de confianza queda patente con el tuteo generalizado: "Reciví tus cartas" (f. 1), "el que te encargo no olvides encomendarlo a Dios en tus oraciones" (f. 2), "Dios y mi Señora de Dolores te sacarán con bien maiormente" (f. 3), "Pata Lolo te saluda" (f. 4), etc.

No sorprende que, dentro de la tradicional fosilización fraseológica, la criolla Rosalía de la Gasca trate a su marido siguiendo el uso típico y representativo del papel que, como mujer, tiene en el contexto matrimonial: "Señor don Rafael de Godoy", "Amado esposo y mui señor nuestro" (f. 13). La despedida es fiel reflejo de la situación de dependencia social y la estigmatización de la frase no deja lugar a dudas: "tu indina esposa que verte decea y tus pies vesa" (f. 15). Si bien en todas las cartas anteriores el centro informativo lo ocupaban las continuadas instancias para que sus parientes acudan a América, en la de esta mujer la petición al marido lleva pareja una defensa de su persona, como mujer nacida en América, y de su unión matrimonial con un castellano, en su sentido más europeo. A esta cuestión se deben los argumentos que plantea con rasgos más cercanos al habla que a la escritura, con afirmaciones que apelan a la complicidad del interlocutor y más propias de un código restringido: "que vien saves que desde la ora y punto que nos casamos no nos faltava qué comer" (f. 13), "que me a costado más orasiones tener carta tulla" (f. 14), y con características coloquiales que se confirman al parafrasear saberes populares: "que tamvién en las Indias ay noblesa como por acá", "y no es señor ni señora el que nase, sino el que lo save ser" (f. 13). Inmersa en este discurso dialógico, como si de una conversación presente se tratara, le recrimina la falta de información, "cuándo bolveré a tener carta tulla", "unos venían y me preguntavan si savía de ti, les desía que no", "y me desían que estavas en Londres, otros que estavas en Giveraltad", "otros que estavas en México, en una tienda", "otros que te avías muerto" (f. 14), y su desazón, "considérame con cada rrasón destas, cómo me quedaría yo", "y más mirando a mi tío y a mi madre, que deseaban saver de ti" (f. 14). La proximidad al registro de habla, con sus mecanismos de comodidad lingüística, explica la discordancia del contexto "que estos papeles que te envío no es más que por darte gusto" (f. 13) y la falta del verbo de lengua en las oraciones: "Don Sevastián, que no dejes de sacarle su fee de bauptismo", "señor Calletano, que no lo olvides y que te acuerdes de lo que le dixistes" (f. 15). Su discurso recurre a la vena más sentimental para convencer a su esposo, que "se bino a estos reinos de Castilla", porque "que nada as perdido ni pierden en que te aygas casado en las Indias" (f. 13). Pone todo su empeño en esta demostración de cariño cuando usa el 
vocativo atributivo, "compañero de mis ojos" (f. 13), "lusero mío" (f. 15), y las evocaciones compartidas, "si tú me tienes presente y de día piensas en mí", "y de noche me sueñas, me pagas con la misma que llo te tengo a ti", "Vibes engañado, que no te echado en olvido" (fs. 13 y 14). En esta relación matrimonial, la mujer tutea a su marido y esta es la forma verbal que se repite en el texto, junto a los marcadores de segunda persona: "receví la tulla", "la dilasión que me sertificas", "mas no por eso te detengas otros tres años", "ni menos me casé contigo por interés de legítima, ni dineros, sino por tu persona" (f. 13), "me pagas con la misma que llo te tengo a ti" (f. 14).

La escritura de estas cartas de mujeres, con la prudencia ante la certeza del amanuense ya aludida, nos permite observar que, más allá de la mayor o menor adecuación a los usos escriturarios, los lapsus cálami responden a un escaso nivel de escolarización, con expresiones vulgares cercanas a la representación del habla de sus autores, especialmente palpable en el escrito de la persona criolla ${ }^{15}$ y de la andaluza gaditana. El reconocido grado de analfabetismo, tanto de la población rural española como de la americana, resulta aún más persistente en el elemento femenino por su endémica marginalidad de los poderes sociales. Cabe esperar, pues, que sus escritos se sitúen en los registros menos formales y coloquiales del habla, con errores ortográficos en nada achacables a meros deslices u olvidos circunstanciales. Así, la impericia en el manejo de las letras y la espontaneidad de las expresiones evidencian que estos documentos aportan diferencias sociolingüísticas por razón de sus redactores, con una proporción de cacografías que prueba la mayor abundancia de descuidos por razón de sexo ${ }^{16}$.

Las cartas de Luisa Yáñez y su esposo revelan una caligrafía cuidada sin apenas errores ortográficos que denoten su falta de dominio o instrucción escolar. Cabe preguntarse si este estado se explica por el hecho de que los escritos, aunque llevan consignada la firma de la mujer, tienen como redactores a los dos cónyuges. Salvo un sintimiento (f. 8) y quizás la falta de concordancia en el adjetivo bastante "con bastante ansias le estamos

15 Recuérdese, al respecto, como comenta Frago (2010: 46), la escasez de individuos criollos, y aún más de población peninsular, frente a la etnia india, mestiza y negra, especialmente en la zona mexicana a la que pertenece esta mujer, Rosalía de la Gasca. No en vano la población autóctona americana, con su diferente distribución geográfica y su relevancia social, ofrece la clave para entender la evolución histórica del dialecto y su contraste en las tierras del Nuevo Mundo.

16 A esta misma conclusión llega Frago (2010: 140) cuando compara escritos de varones, de mayor formación intelectual, con los de algunas mujeres, con peor caligrafía y con más descuidos ortográficos que denotan su vulgarismo fonético. 
esperando" (f. 12), los demás ejemplos que podemos comentar representan formas tradicionales de la lengua que aún perduran, como receví (f. 11), aiga (f. 12), hoy vulgares y rústicas, pero canónicas del español medieval. El mismo término aparece en la misiva de Bernarda Enrique, "resebí la tuia" (f. 5), pero ya encontramos otras cacografías que evidencian su menor atención con olvidos, "estoi rogando a la birgen santima" (f. 5), algunos de posible tendencia dialectal, como las omisiones de implosivas $-s$ y $-d$, "aga esa limona de traerte a Buenos Aires", "quiera la dibina magesta" (f. 5), "estos mal formados renglones llegen a tus [manos] y te allen con la salu que io para mi deseo" (f. 5). La mexicana Rosalía repite el uso de rreceví, rrecevido (f. 13), aunque también muestra reciviéramos (f. 14), y aún emplea el doblete regular escrivido (14). Constatamos el desliz ortográfico del apelativo Getrudes, y la habitual simplificación del grupo consonántico en indina (f. 15), que poco tiene que ver con una falta de competencia. Su escrito, como veremos, sí se halla plagado de cacografías reveladoras de su pronunciación dialectal seseante y yeísta.

En las dos cartas que escribe Isabel Martínez, los lapsus cálami, además de revelar la ascendencia andaluza de su redactora, manifiestan una indiscutible falta de competencia lingüística que la lleva al trueque vulgar del cultismo rediculés (f. 4), al acortamiento de la preposición para y por, "que a todos les cuesta su travajo pa comelo" (f. 3), "po fin" (f. 6), a metátesis y omisiones gráficas, "de benite dos de setiebre", benefiso (f. 7), "nuca pudiera" (fs. 7 y 8), anque (f. 9), algunas de necesaria interpretación, el entender, "y asín que a de estar en el etendre, que si biene biene a estar sugeta a mí" (f. 6), "vuestra merced en el etender que si yo pudiera haser más de lo que hago no lo dejara de aser" (fs. 8 y 9), bejucillo por bejuquillo (f. 10), por por la conjunción causal, "por yo lo ago por ber si a mi lado encuentra una fotuna" (f. 10), etc. A esta falta de escolarización recibida se pueden achacar los continuos errores ortográficos que, por espontaneidad y cercanía con su manera de habla, le provoca el relajamiento de las implosivas: "llegó con felisida", "ute me ase", "asetó a benir" (f. 3), "salu y asieto en todo" (f. 4), "no pierdo las esperasas", "mucha ingratitu" (f. 5), "y co esto seso" (fs. 6 y 10), "quiera Dio" (f. 10), etc. Refrenda lo dicho la rúbrica del final de la carta: "Ysabel Romero y Martisten".

El texto epistolar de Antonia María Manrique, de tono más formal como revela el uso de la captatio benevolentiae con la que se inicia, "estos mal formados renglones llegen a tus [manos] y te allen con la salu que io para mi deseo" (f. 5), está escrito con caligrafía esmerada, sin que se constaten cacografías reveladoras de usos vulgares, aunque aparecen los esperados trueques de explicación dialectal, con registros seseantes y yeístas. 


\section{ASPECTOS LINGÜÍSTICOS}

La cuestión grafemática revela la persistencia de los hábitos más tradicionales en los amanuenses. Las vocales cerradas reflejan aún la costumbre medieval de alternar para la palatal /i/ la i con la jota o con la grafía $y$, especialmente en el inicio de palabra y en diptongos decrecientes, y para la velar /u/ la uve y la u. Luisa Yáñez usa la y en ynfinito (f. 7), yntensiones (f. 8), ynformarse (f. 9); Isabel Martínez escribe ydo (f. 3); en Antonia María Manrique la encontramos en el hiato de la forma verbal oydo (f. 1), y en el adverbio $a h i$, "aunque vengas por ay" (f. 3). También muestran estos usos Bernarda Enrique, con mui (f. 4), Yja, yjo, io, estoi (f. 5), aunque luego alterna "a tu ija" (f. 5) con "yja mía" (f. 7), Rosalía de la Gasca, aygas (f. 13), ysiera (f. 14), o Isabel Martínez, soi (f. 6). Con valor consonántico tenemos la $i$ en las misivas de Luisa Yáñez, "maior estimasión” (f. 7), de Isabel Martínez, traiéndolo (f. 4), y de Antonia María Manrique, maiormente (f. 3).

La indistinción medieval de $\mathrm{b} / \mathrm{v}$ prosigue en los trueques grafemáticos de estos escritos. Luisa Yáñez emplea la $u$ consonántica en fauoresida, sauer, auemos (f. 11), escriuir (f. 13), con el cambio gráfico continuado en la forma rresevido (f. 9) rreceví (f. 11), o en el topónimo La Havana (f. 9), La Hauana (f. 13), etc., y la $v$ con valor vocálico en el indefinido $v n$ (fs. 11 y 13). Contrarios al origen etimológico son los términos dibina, biage, birgen, beras (f. 5) que observamos en la misiva de Bernarda Enrique. También se confirman los trueques en las cartas de Rosalía de la Gasca: receví, rrecevido, aver, vien, saves, faltava (f. 13), escrivido (f. 14), Sevastián (f. 15), pero ba, vibiere (f. 13), vibes, bolveré (f. 14); y de Isabel Martínez: benir, travajo (f. 3), lleuaua, bolutad, bean, vn (f. 4), biera, beo, devo, toabia (f. 5), biene, benir (f. 6), bendiera (f. 9), etc. La carta de Antonia María Manrique reitera estas alteraciones en los términos ya mencionados: rreciví, haverle, tubieran (f. 1), biniendo (f. 3), deves, votica (f. 4).

Perduran aún hábitos tradicionales como el que atañe a la presencia de $n$ delante de las labiales $p$ y $b$. Esta tendencia medieval es la que se deduce del texto de Bernarda Enrique, "sienpre me aconpaña" (f. 5), y de las cartas de Isabel Martínez, tienpo (fs. 3 y 5), anparo, desanpara (fs. 4 y 6), tanbién (f. 5). Por el contrario, la ortografía de Luisa Yáñez concuerda con los usos modernos, compaña, siempre (f. 8) tampoco (f. 12), incluso aparece por la contigüidad fonética $m$ ante $f$, ymformar (f. 13). La misma adecuación caligráfica muestran Rosalía de la Gasca amplia (f. 13), cumpliera, tampoco (f. 14) y Antonia María Manrique, embarcarte (f. 2), acompañarme (f. 3), siempre (f. 4). Todavía, en esta mitad de siglo, constatamos la grafía $q$ latinizante en la misiva de Luisa Yáñez, quales (f. 7), quanto (f. 9), incluso 
contraria a la propia etimología, como escribe Bernarda Enrique, quñada (f. 5). A esta costumbre escrituraria responden las letras, simple o doble, de las consonantes lateral y vibrante en las cartas de Luisa Yáñez, rresevido (f. 9), rrazón (f. 11), socorerla (f. 13), allegré (f. 11), de Bernarda Enrique, José Corea, Enrrique (f. 7), de Isabel Martínez, rreyno (f. 10), o de la criolla Rosalía de la Gasca, rrecevido (f. 13), etc.

En el uso de la grafía $h$, las misivas de Luisa Yáñez y de su esposo responden al mantenimiento de la aspirada procedente de $f$-inicial, con su presencia en las formas verbales hará haser, haremos (fs. 8, 12, 13), incluso en la adventicia, no etimológica, "que esta halle a vuestra merced" (f. 7), "si no hallara alguna conveniensia" (f. 8), y a costumbres grafemáticas medievales cuando omite la originaria latina, o como en el verbo haber ${ }^{17}$, "no a rresevido la carta" (f. 9), "le auemos escrito" (f. 11), "aviendo ocasión" (f. 13), etc., y repite ermana (fs. 7, 9, 11), ermano (f. 11), aunque en la referencia al destinatario, al final, se dice "querida hermana" (f. 9). Hay un ultracorrección en el adverbio "remitir hallá las cartas" (f. 12), y no mantiene la $h$ esperada en el arabismo asta (f. 8). En la carta de Bernarda Enrique, la ausencia de la grafía $h$ es total, tanto en las formas latinas que la llevaban como en la representativa de la aspiración de la $f$-inicial: "Yja i querida", "amado yjo", "te allen con la salu", "lo aremos" (f. 5), "tiene una igita" (f. 7). Ninguna diferencia se detecta en el escrito de Rosalía de la Gasca, que presenta idénticos ejemplos: "tus ermanos", "que nada as perdido ni pierden en que te aygas casado en las Indias" (f. 13), "si así no lo ysiera" "asta que Dios quiso", "avías suplicado" (f. 14), "no ven las oras de verte" (f. 15). Los dos textos de Isabel Martínez muestran casos alternantes para esta grafía: "me ase dél", "lo ubiera dicho", "no se alla el dinero" (f. 3), "quedé sin amparo umano" (f. 4), "soy su hermana", "sé lo que son hijos" (f. 6), "pudiera haser más de lo que hago" (f. 9), etc. La carta de Antonia María a su hijo participa de la ortografía más moderna cuando conserva la $h$ latina y recoge la procedente de la aspirada: "mis hijos", "el haber estado" (f. 1), "has de dejar de pasar", "hermanos y casas" (f. 3), "no hay tiempo para más" (f. 4), aunque también nos muestra la ausencia de la aspirada: "me ha echo mucho provecho" (f. 2).

Las contracciones vocálicas por sinalefa también se dan en los documentos, aunque no con tanta frecuencia como se producían en la

17 Curiosamente, Frago (2010: 123), al comparar las cartas de dos hermanos, Pedro de Oquendo y Juana, de 1725 y de 1721, respectivamente, anota entre las diferencias el hecho de que el hombre pone siempre la $h$ en el verbo haber en tanto que la mujer nunca la usa en esta forma. 
documentación de siglos anteriores. Así se observan en la escritura de Luisa Yáñez, "nunca avido floxera" (f. 11), de Rosalía de la Gasca, "que no te echado en olvido", aunque todavía emplea la forma sin contracción, "y a el fin" (f. 14), o de Isabel Martínez, "tomó dél por istrumeto" (f. 4).

Los trueques gráficos en las sibilantes revelan la ya conformada norma americana, con fenómenos propios del habla de sus individuos. Son escasos los términos que mantienen grafías canónicas medievales. Así, en la carta de Luisa Yáñez aparecen trabaxo (f. 9), quexarse, floxera (f. 11); en la de Antonia María Manrique, rexistros (f. 2) y assí (f. 3). Si en la misiva de Isabel Martínez se escribe Mégico (f. 3), aún sigue usándose $g$ por $j$ en la de Bernarda Enrique, doña Guana, Lugán (f. 5), y como representante de la oclusiva en llegen (f. 5), como sucede también en Antonia María Manrique, pages (f. 4). En todos los escritos, la presencia de los meridionalismos fonéticos prueba la identidad americana de sus registros idiomáticos. Como cabía esperar, los casos de fonetismo seseante serán los más numerosos en nuestras cartas de mujeres. Luisa Yáñez: selebraré, gosando, partisipando (f. 7), yntensiones, paresiere, conveniensia, haser (f. 8), rresevido, ofrese, desir (f. 9), corasón, fauoresida, marso (f. 11), desgrasia, determinasión, sierto (f. 12), fransés (f. 13); Bernarda Enrique: corasón, felis, resebi (f. 5), sinta, dise, seso (f. 7), con grafía ceceante en "para mi conçuelo" (f. 7); Rosalía de la Gasca: marso, goso, dilasión, sertificas, sertificasión, lisensia (f. 13), ysiera, dises, presio, valensiano, conoser, orasiones, felisidad (f. 14), y solo un caso de trueque ceceante decea (f. 15); Isabel Martínez: cajonsito, felisida, ase, desile, pedaso (f. 3), desagradesidos, benefisios, asieto, rediculés (f. 4), sinta, sinco, esperasas (f. 5), reconosimiento, seso (f. 6), rresibi, madresita (f. 7), dosientos, parese (f. 9), donsella (f. 10). Aunque no abundan los ejemplos seseantes en la carta escrita desde La Habana por Antonia María Manrique, bastan con localizar algunos, nesesarias (f. 2), negosios (4), para incluirla en la norma de esta variedad dialectal.

Las muestras de la confusión de las palatales, con profusión de la grafía correspondiente a la lateral, confirman la extensión del yeísmo, que, si bien no se refleja en todos los escritos, no deja duda alguna en el texto de la criolla mexicana, Rosalía de la Gasca, "receví la tulla", "letra tulla", "que te den lo tullo" (f. 13), "me pagas con la misma que llo te tengo a ti", "carta tulla" (f. 14), "que lla no ven las oras de verte", "señor Calletano", "eres la vida sulla" (f. 15); y en la misiva de Isabel Martínez: "y por eya supe quién era" (f. 3), "que lla si fuera vuestra merced sola fuera otra cosa" (f. 6). "y mallormente no abiendo yo traído nada", "yo lla hago lo que puedo" (f. 8), "pues lla sabe vuestra merced lo peligroso que es una donsella" (f. 10). Tampoco se salva del trueque gráfico Antonia María Manrique, "dé orden para que vallas a la Habana" (f. 3). 
Además de la aspiración de la $f$ - inicial latina comentada, las cartas permiten rastrear también la propia del debilitamiento de las implosivas. Quizás sea achacable a una mera falta ortográfica el registro de Bernarda Enrique, "aga esa limona de traerte a Buenos Aires" (f. 5), pero son omisiones más patentes los casos de Isabel Martínez, "le mando vuestra merced 100 pesos y un cajonsito de abanico", "ute me ase dél" (f. 3). La fonética sintáctica puede justificar la ausencia de la ese en "tre rrosario" (f. 10), pero los ejemplos abarcan todos los contextos: emo, digusto, "a los suyo", "Dios, que es padre de pobre" (f. 4), "esas pobre" (fs. 5 y 6), "mi comodidades" (f. 6), "mi hermanas" (f. 10), con el pronombre clítico sin concordancia y con la ausencia en el sustantivo de la marca plural: "de los abanicos, le dará vuestra merced vn par de ellos a las madre de el colegio" (f. 4). También en la carta de esta mujer son numerosos los infinitivos asimilados, desile, comelo (f. 3), grangeale, quitásela, dalle (f. 4), ise (f. 5), mandale, poneme, desilo (f. 9). Refuerza este debilitamiento de las consonantes implosivas la escritura del topónimo Gibraltar en la misiva de la criolla Rosalía de la Gasca, Giveraltad (f. 14).

El empleo reiterado de muncho, con epéntesis nasal, nos confirma la dialectalización de la lengua, con el mantenimiento de este fenómeno de ascendencia regional peninsular, especialmente de la tierras meridionales, tanto en la carta de esta criolla, "y otras munchas que no miento por no conoser a los cavalleros" (f. 14) "Getrudes y don Sevastián se te encomiendan muncho" (f. 15), como en la de la andaluza Isabel Martínez, "le diera muncho más" (f. 5), "darme enfado sino muncho gusto" (f. 8), "munchas memorias" (f. 10).

En cuanto a los rasgos gramaticales, también observamos aspectos lingüísticos conocidos de otras épocas en el español común y ahora mantenidos como elementos caracterizadores de una variedad del sistema, en este caso, la americana. No queda, sin embargo, vestigio alguno de tratamiento voseante, ni siquiera en la misiva fechada desde Buenos Aires. La forma de tratamiento de nuestras mujeres, como hemos comentado, corrobora el uso más común de respeto mediante la fórmula vuestra merced que relacionaba a individuos entre iguales desde el s. XVII, y su evolucionada usted $^{18}$, más propia del registro conversacional (Girón Alconchel 2004: 864),

18 Aunque circunscrito al noroeste argentino, el estudio del corpus epistolar le permite concluir a Fernández Lávaque (2005), que se percibe cierto crecimiento de vos como sujeto pronominal, aunque aún escaso por la falta de prestigio social en esta época, y un descenso de vuestra señoría y construcciones similares, con la práctica ausencia de la forma plural vosotros. A comienzos del siglo XIX predominan las formas de $3^{\mathrm{a}}$ persona singular concordadas 
como aparece en la carta que más elementos coloquiales contiene, la de la gaditana Isabel Martínez: “y por eya supe quién era y la recomendación que ute me ase dél"' (f. 3).

La inherente variación lingüística explica la continuidad de muchos fenómenos de mayor apego a lo tradicional y así se comprueba en las cartas de esta andaluza, que proporcionan contextos en los que se mantiene el uso pleonástico del posesivo analítico: "Madre, llegó con felisida a esta siudad su sobrino de vuestra merced" (f. 3), "su nieto de vuestra merced tiene mil gracias" (f. 5), "yo goso de este benefiso con toda esta su casa" (f. 7). Matiz más coloquial revela la redundancia del clítico junto con el demostrativo en la frase "lo digo esto porque me fue vuestra merced a mandar a su sobrino sin saber vuestra merced si él lo lleuaua a bien o mal" (f. 4), con la perífrasis venir a seguida de infinitivo 'suceder algo que se esperaba o se temía'.

De adscripción medieval y con un uso abundante en el español americano (Kany 1976: 40-41) resultan las construcciones con ausencia del artículo, sobre todo en las referencias temporales, o delante del que relativo, como muestran Rosalía de la Gasca, "que vien saves que desde la ora y punto que nos casamos no nos faltava qué comer" (f. 13), y Antonia María Manrique, "muchas expresiones y agradecimientos por el esmero y cuidado con que tus tíos te han asistido en tu enfermedad" (f. 1).

Igualmente tradicionales resultan los cambios prepositivos observables en las cartas. La presencia o ausencia de la preposición de se constata en Luisa Yáñez, "nuestro maior consuelo será de tenerla en nuestra compaña" (f. 8), "por ella me allegré sauer que gose de perfecta salud", "quexarse que no le han escrito" (f. 11), "estar segura que estamos siempre" (f. 12); en Isabel Martínez, "me alegraré que vuestra merced lo esté" (f. 3), "además que yo no lo traje" (f. 4), "y me devo yo aser el cargo que no la a de dejar vuestra merced que fuera mucha ingratitu" (f. 5); y en Antonia María Manrique, "puede que te acuerdes haverle oydo decir a tu padre y a mí, que nos nos habían dado viruelas" (f. 1). En el escrito de Luisa Yáñez se atestigua aún el empleo de en por $a$, con verbos de movimiento, "si va en Galisia, también soy sierto que se la hará tener" (f. 12) y en otras construcciones menos

con usted y vuestra señoría, pero, al final del período estudiado, se da un equilibrio entre las formas mayoritarias de tuteo y las concertadas con usted. Cabe recordar que Fontanella de Weinberg (1999) manifiesta que vuestra merced se usaba con exclusividad en la relación entre personas ajenas a la familia y entre parientes lejanos y entre cuñados, y que constituía el uso preferente entre hermanos y primos. El pronombre tú se hallaba reducido a una sola relación, de padres a hijos, aunque alterna en la relación pragmática con usted, en este caso apto para la familiaridad afectiva, mientras que tú funciona para la expresión de una relación de enfado y de molestia. 
esperables, pero vigentes en las hablas populares americanas (Kany 1976: 425), "determinarse en venir" (f. 8). El uso contrario de $a$ por en se registra en la carta de Isabel Martínez, "porque asetó a benir a tan mal tienpo" (f. 3). Con respecto a la preposición $a$ para el objeto directo de persona ${ }^{19}$, aún alterna con la ausencia. Si Bernarda Enrique hace uso de esta marca, "estoi rogando a la birgen santima" (f. 5), en otras cartas se elige su omisión, como en la de Isabel Martínez, "parese que vuestra merced no conose la hija que tiene" (f. 9), "le remitiré vuestra merced dosientos pesos" (fs. 9 y 10), y en la de Rosalía de la Gasca, "Juan Soltero del Toro, el cual le merecí el que me escriviera" (f. 14). La preposición superflua aparece en la carta de Luisa Yáñez, "quiera a Dios que su determinasión que se[a] quanto antes" (fs. 12 y 13), con un uso pleonástico del nexo subordinante. Y es también en su escrito donde se detecta el empleo tradicional de quien, con antecedente de cosa, vigente aún en el s. XVII (Girón Alconchel 2004: 871), pero observable en siglos posteriores (Frago 2010: 103-107), "que ahora va otra de vn mes antes, que se escriuió en quien el sobre escrito va a don Antonio Marcos" (fs. 11 y 12).

Presente en el lenguaje coloquial, y muy extendido en las hablas populares americanas, resulta la forma analógica con $-s$ final de la segunda persona del pretérito. Es la terminación que prefieren la criolla Rosalía de la Gasca, "si con estos papeles no negosias nada, ni tus ermanos se ablandan, vente como te fuistes" (f. 13), Antonia María Manrique, "no has de dejar de pasar por donde pasastes todos tus trabajos" (f. 3). La auxiliaridad muestra los casos coexistentes aún en el siglo XVII (Girón Alconchel 2004: 869), y hoy dialectal en Andalucía y América. A esta variedad se adscriben los usos de Luisa Yáñez, "soy sierto que se la hará tener" (f. 12), "le auemos escrito" (f. 11), "auemos sentido mucho de que vuestra merced aiga salido de esa casa" (f. 12), "Barada, vn panadero fransés, porque entonses haremos de escriuir a esa señora" (f. 13), y de Isabel Martínez, "mire vuestra merced si no auemos tira a no dalle digusto" (f. 4). La carta de Rosalía de la Gasca acoge la asociación a la construcción fija "aver menester" (f. 13), además del tradicional haiga, con el infijo velar, presente en el habla popular de dialectos meridionales y americano, "que nada as perdido ni pierden en que te aygas casado en las Indias" (f. 13).

También el mayor uso de -ra frente a -ría, se justifica por la tipología más informal de estos escritos (DeMello 1997) y es lo que se confirma en

19 Quesada Pacheco (2002: 113-114) estima que la estructura asindética en el objeto directo de persona, en el dativo personal y en las perífrasis verbales, se da entre hablantes de menor nivel de escolarización de toda América. 
Rosalía de la Gasca, "que fuera de que te estimo y te quiero, no cumpliera con lo que Dios me manda si así no lo ysiera" (f. 14) y en Isabel Martínez, "quien le da esos, si pudiera, le diera muncho más" (f. 5), "que lla si fuera vuestra merced sola fuera otra cosa" (f. 6), "vuestra merced en el etender que si yo pudiera haser más de lo que hago no lo dejara de aser" (fs. 8 y 9), "si posible fuera, las alagitas que tengo las bendiera para mandale vuestra merced su produto, anque yo no tubiera qué poneme" (f. 9).

La presencia del futuro de subjuntivo, frecuente en los clásicos, nos previene del comentario tan generalizado de su falta de productividad, especialmente en textos americanistas y más cercanos al lenguaje hablado (Kany 1976: 225-226). Los ejemplos se rastrean en todas las misivas: Luisa Yáñez, "en eso hará lo que mejor le paresiere", "quisiere determinarse en venir" (f. 8); Rosalía de la Gasca, "mientras vibiere mi señora madre y tíos no nos faltará qué comer" (f. 13); Isabel Martínez, "si ute quisiere mandarme a Joaquina me la puede vuestra merced mandar" (f. 6); Antonia María Manrique "y por si acaso yo no tubiere tiempo" (f. 1), "embarcarte con todas las comodidades que fueren nesesarias" (f. 2).

Los cambios de modo y de tiempo, presentes en contextos medievales, aunque con persistencia en las variedades andaluzas y extremeñas, y con extensión probable a las tierras americanas, como comenta Lapesa (2000: 726), los confirmamos en la carta de Luisa Yáñez: "conque es desgrasia nuestra de que las cartas se pierden" (f. 12), "aviendo ocasión y pudemos socorerla lo haremos" (f. 13), "lo que vuestra merced puede haser en el tiempo que se quedará en Cádiz", "para que las cartas no se perderán" (f. 13).

A la preferencia del adverbio acá, recogido en las cartas de Luisa Yáñez, "venir por acá" (f. 8), de Isabel Martínez, "que acá no se alla el dinero en la calle" (fs. 3 y 4), de Antonia María Manrique, "para que en los primeros rexistros que salgan para acá" (f. 2), "por acá quedan todos buenos" (f. 4), siguen usos más propios del registro coloquial, como el de fuera de 'además de' en Rosalía de la Gasca, "que fuera de que te estimo y te quiero, no cumpliera con lo que Dios me manda" (f. 14), o como el de la acomodación del adverbio así con $-n$ para evitar la vocal tónica final, hoy vulgar, que se muestra en Isabel Martínez, "y asín póngase vuestra merced en mi lugar" (f. 8). Además se constatan la pervivencia del intensificador infinito en la carta de Luisa Yáñez, "selebraré ynfinito que esta halle a vuestra merced gosando la que nuestro maior cariño desea" (f. 7), y la intensificación del adjetivo en la construcción popular que emplea Isabel Martínez, "como esas pobre de mis hermanas" (f. 5).

De reminiscencia tradicional se tachan la doble negación, utilizada por Luisa Yáñez, "que de casa de tía María tampo[co] se a recevido carta ninguna" (f. 12), y las construcciones completivas sin nexo (Girón Alconchel 
2004: 879-880), más comunes en el dialecto americano que en la Península, que vemos en el contexto de la despedida de Bernarda Enrique, "y seso no de rogar a Dios te guarde felizes años" (f. 7), y de Isabel Martínez, "rogar a Dios guarde vuestra merced mil años" (f. 6).

La norma respetuosa en las funciones de los clíticos se manifiesta, por ejemplo, en las cartas de Luisa Yáñez, "la estiman y verla desean" (f. 9), socorerla (f. 13), de Bernada Enrique, "le tengo prometido a la birgen de Lugán de irle a serbirla con bos propia", "le estoi sirbiendo a la birgen" (f. 5), pero el leísmo de persona, que, según Kany (1976: 133-139), ya alternaba en la escritura y ocasionalmente en el habla culta, aparece en el texto de Antonia María Manrique, disgustarle (f. 4), con un ejemplo de le invariable, mayoritariamente en función catafórica, que se percibe en las hablas populares peninsulares y americanas, "que te acuerdes haverle oydo decir a tu padre y a mí que no nos havían dado viruelas" (f. 1), y que también se observa en el escrito de Isabel Martínez, aunque con la cautela que exige el análisis de esta carta, atestada de omisiones consonánticas: "a todas mi hermanas le dé vuestra merced munchas memorias" (f. 10).

Si los ejemplos de diminutivo confirman la emotividad de las cartas, con un carácter afectivo en la misiva de Bernarda Enrique, "tiene una igita" (f. 7), y con matiz de expresividad en la de Isabel Martínez, "cajonsito de abanico" (f. 3), "alagitas que tengo" (f. 9), con idéntica función en el empleo del superlativo en el escrito de Rosalía de la Gasca, "la cual rreceví con muchísimo goso" (f. 13), el campo semántico de este pequeño corpus epistolar restringe, hasta cierto punto, el léxico empleado, más encaminado a la demostración afectiva e íntima, como testimonian los términos ya aludidos, especialmente en los saludos y despedidas de las cartas. En este sentido, se justifica el uso del verbo encomendar que hace Isabel Martínez, "bien puede vuestra merced encomedar a Dios que le dé salu" (f. 4), construido con dativo ético en las misivas de Bernarda Enrique, "todas se te encomiendan de corasón" (f. 7), y de Rosalía de la Gasca, "Getrudes y don Sevastián se te encomiendan muncho" (f. 15), quien igualmente construye el verbo soñar como transitivo, conocido en México y América Central, según Kany (1976: 407), "de noche me sueñas" (f. 14), y defiende con vehemencia su honestidad al reforzar el adjetivo fiel con el término fino 'constante en el amor', "ni tampoco me presio de incostante, sino de fiel y de fina" (f. 14). Aunque Luisa Yáñez hace gala de un estilo más elaborado con la referencia metonímica a la carta, aquí llamada favoresida, y con la alusión al tercer mes del año con el participio de presente cadente, ya anticuado, "Receví su fauoresida, fecha de 28 de marso del cadente" (f. 11), "se las remitirá en manos propio" (f. 12), sus ejemplos descubren el contexto más sentimental e íntimo con el mantenimiento de refuerzo identificativo propio 'mismo', y con el uso 
popular en andaluz y americano del verbo extrañar 'echar en falta', "no estrañará nunca la casa de sus padres" (f. 8). También Rosalía de la Gasca hace uso de las acepciones primitivas de merecer, intimar o del preferente mentar por nombrar, más popular, igual que la locución adverbial a ratos: "Juan Soltero del Toro, el cual le merecí el que me escriviera intimándome lo que tú le avías suplicado", y otras munchas que no miento por no conoser a los cavalleros", "aunque dises que aunque sea a ratos me acordaré para encomendarte" (f. 14).

No es ajeno este apartado léxico al registro coloquial cuando en la carta que demuestra un mayor nivel educacional, la de Antonia María Manrique, se hace uso de la expresión "está corriendo con los negosios de tu padre" (fs. 3-4) y se utiliza el término pata 'amigo íntimo, compañero inseparable', recogido en el Diccionario de Americanismo académico como de uso popular en Cuba, Perú, el suroeste de Bolivia y Chile, aunque el $D H$ añade Argentina y otros, "Pata Lolo te saluda y dice que por tener correo mui largo no te escribe" "Pata Pepe dice que él salió bien de su tabardillo" (f. 4), contexto en el que aparece la denominación más popular del tifus, hoy desusada, de tabardillo. También este carácter popular del léxico está presente en Bernarda Enrique, que recurre al hipocorístico para llamar a una de sus parientes, "de parte de tu tía Pancha que se encomienda mui de beras" (f. 5).

La propia base informativa de las cartas, el viaje hacia las Indias, explica la presencia de términos marineros y el conocimiento generalizado de los condicionantes de la travesía. Así, Antonia María Manrique se permite aconsejar a su hijo, en su vuelta por La Habana, que "no has de dejar de pasar por donde pasastes todos tus trabajos, más bien si no pasarás biniendo en derechura para el Golfo" (f. 3), y emplea el término registros para referirse al buque que transportaba las mercancías, registradas para el pago de sus derechos, en el comercio con las Indias, aunque ya el $D M$ lo tacha de anticuado, "para que en los primeros registros que salgan para acá, disponga el embarcarte" (f. 2).

Queda igualmente constancia del uso preferente americano del término lindo en el escrito de Isabel Martínez, "es tan lindo que me alegrara que vuestra merced lo biera" (f. 5), que reconoce también los abalorios comunes de la China como el bejuquillo "cadena de oro con que se adornan el cuello las mujeres', "un bejucillo y un relicario y tre rrosario de plata" (f. 10). De la criollización y del aindiamiento del español americano da fe el quechuismo china 'criada', que aparece en la misiva de Bernarda Enrique, residente en Buenos Aires, lejos de la primitiva zona de influencia quechua, "la china sienpre me aconpaña" (f. 5). 


\section{CONCLUSIÓN}

Parece aventurado pretender formular conclusiones acerca de los contrastes lingüísticos manifiestos en las misivas de las mujeres que escriben o responden a sus maridos y parientes emigrados al Nuevo Mundo. Apenas tenemos noticias de este intercambio epistolar por la propia razón de sus finalidades personales e íntimas, y, fundamentalmente, no podemos analizar las cartas como escritos personales de las supuestas firmas femeninas, en un contexto en el que la escritura quedaba reservada en muchos casos a unos pocos hombres privilegiados, incluidos en las redes de una administración impuesta o bajo la autoridad eclesiástica que exigía un mínimo de rudimentos culturales para su acogida fraternal en el destino evangelizador. No cabe duda, por la simple comprobación caligráfica, del mero dictado de muchas de ellas, sujetas entonces a los moldes escriturarios aceptados y repetidos por los escribanos concertados. No obstante, si bien la estructura responde a la tipología del escrito, el contenido obliga al amanuense a expresar los deseos y las particularidades de la responsable del dictado epistolar.

La lengua de estas cartas muestra la preferencia de sus autoras por expresiones y términos de intensificación afectiva, todos con fuerte contenido emocional por el saber compartido de sus interlocutores, pero circunscritos al contexto de un registro coloquial definido por el tipo de escrito, esto es, por la carta privada, que se desarrolla con las inferencias pragmáticas y las interpelaciones al interlocutor como conversación recreada, y por el nivel informal en el que se sitúan. Es este contexto el que justifica la espontaneidad de sus términos, con los errores caligráficos que denotan el vulgarismo expresivo de sus amanuenses, además de su adscripción a una norma dialectal definida, o el acopio continuado de mecanismos de comodidad lingüística, como son los abundantes elementos fraseológicos y estereotipados tanto de índole popular o conversacional como tipológicos de la estructura de una carta.

A este discurso femenino pertenecen las expresiones sentimentales de la cortesía interesada, es decir, de los tratamientos y de las apelaciones más familiares. Que se trata de una cuestión de preferencia y no de un recurso exclusivo por razón del sexo se demuestra con los citados diminutivos de los que se valen Isabel Martínez y Antonia María Manrique, madresita, mamaíta, o el apelativo cariñoso que la criolla Rosalía de la Gasca dedica a su marido, lusero, todas expresiones más frecuentes y habituales del habla de una mujer. En la relación entre los interlocutores, se confirma una mayor familiaridad y cercanía afectiva en las cartas de madre a hija, e incluso a hermana, al tiempo que se evidencia cierto distanciamiento admitido cuando se le escribe 
a un hijo y/o al marido, en este último caso, como hemos comentado, con desigualdad manifiesta claramente subordinante del papel social de la mujer. En el tratamiento, el uso más común de respeto se reproduce mediante la fórmula vuestra merced que se emplea en la relación de Isabel Martínez con su madre, en la que también se registra la forma evolucionada usted, y en la de Luisa Yáñez con su hermana, siempre con las marcas discursivas deferentes de tercera persona. En las misivas de Bernarda Enrique a su hija y de Antonia María Manrique a su hijo, el esquema de mayor confianza se manifiesta con el tuteo continuado, que es el tratamiento exclusivo que da también la criolla Rosalía de la Gasca a su marido.

La consustancial variedad de normas de los escritos resulta palpable tanto en el mantenimiento de rasgos de adscripción medieval como en los que denotan una impronta más innovadora. En el apartado grafemático, muchos lapsus cálami obedecen a la vinculación del texto escrito a los fenómenos prosódicos de la oralidad, vinculados, eso sí, a una falta de instrucción escolar que produce confusiones de consecuencias vulgares. Si aún persisten hábitos escriturarios tradicionales, la presencia de determinadas grafías permite deducir la adscripción dialectal de sus normas de habla y, en este caso, tanto las mujeres de ascendencia peninsular como la nacida en América participan de los fenómenos caracterizadores de la variedad lingüística americana, con predominio de los denominados meridionalismos fónicos, como son el seseo generalizado de todos los escritos, la aspiración y el debilitamiento de implosivas, o el yeísmo más reiterado en las cartas de la andaluza gaditana Isabel Martínez y de la criolla mexicana Rosalía de la Gasca.

Las variantes gramaticales y léxicas observables en estas misivas confirman fenómenos de tradición histórica en nuestra lengua no privativos de un registro coloquial sino reveladores de parámetros diastráticos y diatópicos, en este caso del nivel más popular y de la modalidad americana. Los contrastes prepositivos, el empleo etimológico de los clíticos, la preferencia en los modos verbales o la presencia del futuro de subjuntivo, por ejemplificar con algunos de los fenómenos mencionados, confirman la tradición histórica de esos usos y su arraigo en esta variedad dialectal. Incluso en el apartado léxico, escasamente representado en este corpus, por razón de su tipología, se perciben la preferencia por acepciones más tradicionales y la introducción de americanismos, así como la aceptación plena de terminología indígena, como la de la voz china.

Cabe reiterar, por último, que si el carácter privado de los textos y la relación afectiva entre los interlocutores justifican la intensidad sentimental de los términos, adscrita al entorno femenino como rasgo preferente, muchas de las expresiones y de los usos fraseológicos con los que nuestras mujeres se expresan encajan en los mecanismos conversacionales de estas 


\section{cartas, como formas que incentivan y reproducen el supuesto diálogo en la distancia.}

\section{REFERENCIAS BIBLIOGRÁFICAS}

Bentivoglio, Paola. 2002. Formas de tratamiento en cartas de la segunda mitad del siglo XVI: una aproximación pragmática. En Rosa M. ${ }^{a}$ Castañer y José M. ${ }^{a}$ Enguita (eds.). In Memoriam Manuel Alvar (1923-2001), Archivo de Filología Aragonesa, LIX-LX, pp. 229-248.

Boyd-Bowman, Peter. 1975. A sample of sixteenth century 'Caribbean' Spanish phonology. En Colloquium on Spanish and Portuguese Linguistics. Washington: Georgetown University Press, pp. 1-11.

Cano Aguilar, Rafael. 2000. Introducción al análisis filológico. Madrid: Castalia.

DeMello, George. 1997. Formas verbales en -ra / -se con valor de condicional. En George DeMello y Josse de Kock, Lengua escrita y habla culta en América y España. Diez casos. Salamanca: Ediciones Universidad de Salamanca, pp. 39-51.

Fernández Lávaque, Ana M. ${ }^{a}$. 2005. Estudio sociohistórico de un proceso de cambio lingüístico. El sistema alocutivo en el Noroeste argentino (Siglos XIX-XX). Salta: Universidad Nacional de Salta y Universidad de Buenos Aires.

Fernández Navarrete, Martín. 1831. Diccionario marítimo español. Madrid. Ed. 1974. (DM).

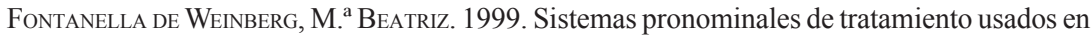
el mundo hispánico. En Ignacio Bosque y Violeta Demonte (drs.). Gramática descriptiva de la lengua española. I. Sintaxis básica de las clases de palabras. Madrid: Espasa Calpe, pp. 1399-1425.

Frago Gracia, Juan Antonio. 1987. Una introducción filológica a la documentación del Archivo General de Indias. Anuario de Lingüística Hispánica, III, pp. 67-97. 1999. Notas sobre el español antillano del siglo XVI en cartas de emigrados andaluces. En Amparo Morales (ed.). Estudios de lingüistica hispánica: Homenaje a Maria Vaquero. San Juan de Puerto Rico: Universidad de Puerto Rico, pp. 250-262. Chilena de Ediciones.

Franco Figueroa, Mariano. 2010. La huella de los jiennenses en la América colonial. A propósito del seseo. En M. ${ }^{a}$ Isabel Sancho Rodríguez y Carmen Conti Jiménez (eds.). Nuevas aportaciones al estudio del seseo. Jaén: Servicio de Publicaciones de la Universidad de Jaén, pp. 71-104.

García Moutón, Pilar. 1999. Cómo hablan las mujeres. Madrid: Arco/Libros. 1999a. Tratamiento en las cartas de Indias. En Amparo Morales (ed.). Estudios de lingüistica hispánica: Homenaje a María Vaquero. San Juan de Puerto Rico: Universidad de Puerto Rico, pp. 263-276.

Girón Alconchel, José Luis. 2004. Cambios gramaticales en los Siglos de Oro. En Rafael Cano Aguilar (coord.). Historia de la lengua española, Barcelona, Ariel, pp. 859-893.

Kany, Charles. 1976. Sintaxis hispanoamericana. Madrid: Gredos.

Lapesa Melgar, Rafael. 2000. Sobre el uso de modos y tiempos en suboraciones de acción futura o contingente. Futuro de indicativo por presente o futuro de subjuntivo. En Rafael 


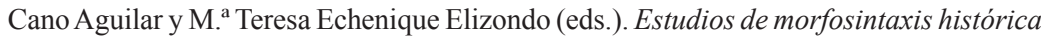
del español, t. II. Madrid: Gredos, pp. 705-729.

Macías, Isabelo y Francisco Morales Padrón, 1991. Cartas desde América. 1700-1800. Sevilla: Junta de Andalucía, Consejería de Cultura y Medio Ambiente.

Martín Zorraquino, M. a Antonia. 1993. Observaciones sobre las propiedades atribuidas al habla femenina en el ámbito hispano. En Actas del I Congreso Anglo Hispano. Madrid: Castalia, pp. 115-126.

1999. Oralidad y escritura en el discurso femenino, en Joaquín Garrido Medina (coord.). La lengua y los medios de comunicación. Actas del Simposio Internacional, vl. I. Madrid: Servicio de Publicaciones de la Universidad Complutense de Madrid, pp. 23-45.

Osterreicher, WUlf. 2004. Textos entre inmediatez y distancia comunicativas. El problema de lo hablado escrito en el Siglo de Oro, en Rafael Cano Aguilar (coord.). Historia de la lengua española. Barcelona: Ariel, pp. 729-769.

Otte, EnRiQue. 1996. Cartas privadas de emigrantes a Indias (1540-1616). reimpresión en México: Fondo de Cultura Económica.

Quesada Pacheco, Miguel Ángel. 2002. El español de América. Cartago: Editorial Tecnológica de Costa Rica.

Real Academia Española, Asociación de Academias de la Lengua Española. 2010. Diccionario de americanismos. Lima: Santillana Ediciones. $(D A)$.

Richard, Renaud. 1997. Diccionario de hispanoamericanismos no recogidos por la Real Academia. Madrid: Cátedra. $(D H)$.

Ruiz Fernández, Francisco. 2002. Fonética del español de América del s. XVI en cartas de emigrados andaluces a Indias, ed. electrónica. Cádiz: Servicio de Publicaciones de la Universidad de Cádiz. 